\title{
Signos distintivos en comunidades ruRales de Baja California Sur, MÉXICO: UNA ESTRATEGIA PARA IMPULSAR EL TURISMO RURAL
}

\author{
Alba E. GÁmez \\ agamez@uabcs.mx \\ EDUARDO JUÁREZ \\ lalo@uabcs.mx \\ Departamento Académico de Economía \\ Universidad Autónoma de Baja California Sur \\ José Alfredo Guevara-Franco \\ jguevara@uabcs.mx \\ Departamento Académico de Ciencia \\ Animal y Conservación del Hábitat \\ Universidad Autónoma de Baja California Sur
}

En este artículo se ofrece una reflexión sobre las posibilidades que da la figura de signos distintivos a alimentos para potenciar el turismo rural en San Miguel y San José de Comondú, dos localidades serranas aisladas que conforman Los Comondú, uno de los oasis de mayor importancia en la parte sur de la península de Baja California, en el noroeste de México. En ambas comunidades, los productos agropecuarios representan un valor significativo para la economía familiar. Sin embargo, es preciso replantear sus procesos de organización y de producción para revalorar el patrimonio gastronómico, así como cuidar la inocuidad de los productos. Esto prepararía a los pobladores locales para incursionar en nuevos nichos de mercado e incorporar valor agregado a productos ya existentes, lo que a la vez apoyaría las iniciativas de turismo rural en la zona.

Palabras clave: México, alimentos, signos distintivos, turismo rural.

\section{DistinCTIVE SIGNS IN RURAL COMMUNITIES OF}

\section{Baja California Sur, Mexico: a strategy to promote rural tourism}

This paper reflects on the possibilities given to food products by distinctive signs or trademarks to strengthen rural tourism in San Miguel and San José de Comondú area, two geographically isolated mountain towns that form Los Comondú, one of the most important oases in the southern part of the Baja California peninsula. Agricultural products are a key asset for the economy of families in the region; however, the organization and production processes should be reconsidered for the revaluation of their gastronomic heritage including the improvement of measures related to food safety. These strategies would prepare the local population to venture into new market niches and add value to the existing food products, and at the same time, it could support rural tourism initiatives in the region.

Keywords: Mexico, distinctive signs, food, rural tourism. 
E n este artículo se ofrece un análisis respecto a las posibilidades de reactivación económica ligadas al empleo de signos distintivos en la producción de alimentos en zonas rurales remotas, que fortalezcan las economías locales y permitan elevar el nivel de vida de sus habitantes, usando el caso de las localidades de San Miguel y San José de Comondú (Los Comondú), ubicadas en Baja California Sur, en el noroeste mexicano. Los signos distintivos, como marca colectiva (MC) y denominación de origen (Do), presentan una dimensión que supera el ámbito meramente económico para entroncar con aspectos sociales y culturales, y son considerados un factor importante que contribuye al desarrollo rural de regiones periféricas, aprovechando el potencial de nichos de mercado para estos productos (Granados y Álvarez, 2004).

En particular, el uso de las gastronomías locales asociado al turismo es entendido como un mecanismo benéfico de diversificación de las actividades productivas locales, en la medida en que no las sustituya sino que las complemente (Millán Vázquez de la Torre y Agudo, 2010). De esa manera, las posibilidades de empleo e ingreso ayudan a evitar la expulsión demográfica y la falta de desarrollo, que afectan a una vasta proporción de las comunidades rurales. Además, la reevaluación del patrimonio gastronómico puede desplegar efectos positivos sobre la conservación de los recursos naturales en las zonas rurales al estimular su buen aprovechamiento, toda vez que en ellos se basa la preparación de alimentos.

Por ejemplo, se adelanta que las Do permiten una mejor conservación de las especies de razas y variedades criollas, al rescatar elementos como su antigüedad y su significado patrimonial natural y cultural, en comparación con los sistemas intensivos y modernos de producción. De alguna forma, podría considerarse que la Do mantiene colecciones in situ, sin proponérselo. Es así que, en Europa, las indicaciones geográficas (IG) de alimentos y las Do se estiman importantes por sus efectos ambientales, como la conservación del paisaje, del suelo y de las especies nativas originales (Millán Vázquez de la Torre y Agudo, 2010).

En el caso de Baja California Sur, su aislamiento geográfico y naturaleza geológica han favorecido la existencia de pequeños valles delimitados por cañadas. En ellos, comunidades aisladas mantienen una riqueza gastronómica centenaria ligada a actividades agropecuarias sostenidas desde la época de la presencia jesuita en la región durante los siglos XVII y XVIII. De ese tiempo se conservan, entre otros elementos patrimoniales, una misión de piedra, acequias, y el sistema de huertas y ganadería aún en funcionamiento. Varios productos podrían ser potenciales candidatos de protección legal en Los Comondú, lo cual favorecería abonar a la conservación de especies de valor cultural y ambiental, y proteger un patrimonio común en esas localidades. Sin embargo, es necesario reducir la heterogeneidad en la calidad de los productos, y generar estudios de ubicación geográfica, calidad e inocuidad como estrategias de intervención que estén anclados, por ejemplo, al turismo rural (Guevara, Juárez, Gámez y Rojas, 2013). Lo anterior permitiría ofrecer alternativas de reactivación para esa zona económicamente deprimida y rescatar modos de vida con un alto valor cultural.

Las comunidades de San Miguel y San José de Comondú están enclavadas en la sierra La Giganta, a una distancia de 130 kilómetros de Ciudad Constitución, cabecera del 


\section{A. E. Gámez · E. Juárez · J. A. Guevara-Franco}

municipio de donde dependen administrativamente estos poblados. A mitad de 2011 se concluyó el tramo carretero que comunica a Los Comondú con la localidad de Francisco Villa, ubicada a 37 kilómetros de distancia de los dos poblados. Justo ahí está la intersección con una carretera que conduce a La Purísima y a San Isidro, hacia el norte, y a Ciudad Insurgentes, hacia el sur. En este último asentamiento, la ruta se entronca con la carretera transpeninsular, eje de las comunicaciones por tierra de la entidad.

San Miguel y San José se encuentran separados entre sí por un camino vecinal de tres kilómetros de distancia, dentro de una cañada de 16 kilómetros de longitud que tiene una superficie de 88 hectáreas, deshabitada en su mayor parte. La zona cuenta con un arroyo superficial, el arroyo Comondú, que se nutre del agua que brota de varios manantiales repartidos a lo largo de su recorrido. Los Comondú son, literalmente, un oasis en el semidesierto sudcaliforniano; un socioecosistema valioso no solo ambiental sino culturalmente. El arroyo Comondú forma un humedal que fue designado sitio Ramsar el 2 de febrero de 2008 por su alto valor ecosistémico, el cual hospeda a siete especies de aves y 18 de reptiles bajo algún estado de protección en la NOM-059-SEMARNAT-2001, y es sitio de descanso para especies migratorias (Breceda, Galina y Cortés, 2010).

La estructura productiva en estas comunidades descansa en el sector primario: las dos actividades que le dan viabilidad a sus economías son la ganadería y la agricultura. Cabe mencionar que, en San Miguel de Comondú, la producción agrícola es más importante que la ganadería, porque el suelo es menos salino, lo que permite una mayor fertilidad y mejores cosechas; en el caso de San José, la ganadería (y la producción de queso) representa la actividad sobresaliente. Sin embargo, en ambas comunidades coexisten otras prácticas productivas que complementan el ingreso de sus habitantes, como la fabricación de dulces regionales, vino, y algunas artesanías que venden a los visitantes (Gámez, 2013). Asimismo, los programas gubernamentales de apoyo rural constituyen una fuente monetaria significativa en la forma de programas de empleo temporal y capacitación para la conservación ambiental y el desarrollo local (Peninsular Digital, 2011).

En los últimos años, el gobierno estatal ha promovido el turismo en las zonas serranas ligado a la producción artesanal del vino misional, a la confitería con frutas locales, a las figuras del oasis y el rancho sudcaliforniano. Los mecanismos han sido la organización de festivales del vino, los apoyos a fondo perdido para la elaboración de alimentos y la construcción de cabañas, la construcción de vías de comunicación y el mantenimiento de la infraestructura en la zona central de los dos pueblos, así como el financiamiento para la investigación a través de las convocatorias de fondos mixtos (Gámez, 2013; Coordinación General de Desarrollo Sustentable, 2015). Tales iniciativas, acompañadas de algunos esfuerzos privados, han derivado en resultados heterogéneos respecto al turismo rural: hay un hotel, que promociona un museo, con habitaciones dobles y sencillas, servicio de internet, cocineta equipada, aire acondicionado y televisión por cable, además de alguna otra oferta de alojamiento en cabañas y de servicios de alimentos; ciclismo de montaña; caminata; cabalgatas; exhibiciones y festivales de tradiciones locales; pero lejos están aún la activación de las huertas o la integración de las actividades primarias y productos 
artesanales tradicionales en una oferta turística consolidada. Con todo, el discurso del potencial turístico de los oasis sigue siendo incluido en la política pública estatal (Consejo Nacional de Ciencia y Tecnología, 2018).

Esta investigación ofrece una reflexión sobre las posibilidades que pudieran surgir para los productores artesanales de San Miguel y San José de Comondú a partir de la incorporación de valor agregado a productos agropecuarios ya existentes, como el queso de cabra y el vino misional; lo que a la vez apoyaría las iniciativas de turismo rural en la zona. Esa reflexión se basa en el trabajo de campo realizado por los autores en Los Comondú entre 2012 y 2013, que incluyó el análisis de cepas de ambos productos, y en subsecuentes visitas de investigación en 2014 y 2016, las cuales derivaron en la observación de los procesos productivos y festivales del vino y de la fruta; en entrevistas a rancheros productores de queso en ambas comunidades, y de vino en San Miguel, así como a pobladores participantes en las actividades de alojamiento y preparación de alimentos, también en esta última localidad.

El texto está dividido en tres partes tras esta introducción. La primera expone una revisión del turismo rural como elemento de dinamización económica en zonas apartadas; la segunda se refiere a las oportunidades económicas que ofrecen los signos distintivos para la comercialización de productos y servicios artesanales; la tercera aborda las características del queso de cabra y del vino misional de Los Comondú, productos que podrían comercializarse con signos distintivos como el de una mc. También se incluyen algunas consideraciones finales sobre los elementos que habría que contemplar para aprovechar las condiciones de ventaja que poseen los productos agropecuarios artesanales de Los Comondú en términos de la aceptación que tienen entre los consumidores del estado, y del reconocimiento de su valor cultural asociado con la cultura ranchera sudcaliforniana y del oasis.

\section{El turismo rural como una alternativa de dinamización en zonas apartadas}

Uno de los sectores de mayor dinamismo en la estructura económica mundial es el turismo, de manera que se ha convertido en un factor importante en cuanto mecanismo para la diversificación económica y la captación de divisas. En el ámbito internacional, en los primeros cuatro meses de 2018, el arribo de turistas creció 6 \% con relación al año anterior, superando las expectativas de 4 \% que contemplaba la Organización Mundial de Turismo para 2018 (Organización Mundial de Turismo, 2018). Los recursos generados de ese crecimiento significaron el equivalente a $30 \%$ de las exportaciones mundiales de servicios, y casi $70 \%$ para los países en desarrollo en este mismo rubro, lo que lo ha constituido en fuente principal de ingreso para estos países.

Sin embargo el turismo, por lo general identificado con su vertiente "tradicional" (esto es, masificado, del cual el tipo de sol-playa es representativo), está sujeto a "filtraciones" 
económicas asociadas con la repatriación de ganancias, y a dos factores estrechamente relacionados: la especulación con el precio de la tierra y el cambio de uso del suelo para fines de explotación turística (Dávila López, 2014; Brenner y Aguilar, 2002). Esto suele tener efectos adversos sobre los ecosistemas de las regiones donde se inserta (Ibarra Núñez, Gámez y Ortega-Rubio, 2018) y sobre las sociedades ahí establecidas; si bien, en este último sentido, se ha registrado dualidad en torno a las percepciones de tales afectaciones (Monterrubio, Osorio y Benítez, 2018).

Con base en esas consideraciones, acompañar el análisis de las actividades turísticas desde una perspectiva económica, medioambiental y de las relaciones sociales es relevante, en especial respecto a comunidades pequeñas (Mckercher y Du Cros, 2002; Rosas Mantecón, 2006). De tal modo, pueden plantearse formas alternas para aprovechar el potencial turístico en un marco de respeto del medio natural, orientando políticas públicas dirigidas a las actividades del sector turístico en apoyo de proyectos productivos en y para las comunidades locales. Es en este contexto que, en las últimas décadas, ha surgido una corriente para promover y practicar turismo, así como ofrecer servicios turísticos de una manera diferente de la masiva. Ello ha dado cabida a una amplia diversidad de formas de realizar actividades turísticas no convencionales, que incluyen la apreciación de atractivos naturales y manifestaciones culturales con un bajo impacto ambiental y cultural.

Así, la tendencia creciente a experimentar entornos distintos de los urbanos ha propiciado la diversificación de actividades turísticas ligadas a lo cultural (formas de vida, costumbres, alimentos) en las zonas rurales. Aunque el turismo rural no es nuevo, su novedad en la actualidad reside en las características de los turistas (mayor conciencia ambiental e ingreso, demanda de mejor calidad, entre otros factores); lo cual requiere de estrategias para convertir los recursos (naturales, patrimoniales) en productos turísticos (García Henche, 2005, p. 115). Sin embargo, usar esos recursos garantizando el desarrollo de las comunidades rurales y conservando la autenticidad de las experiencias, productos y servicios rurales precisa resaltar el vínculo entre las personas, los lugares y los productos (Vandecandelaere y Abis, 2012).

Pese a lo anterior, con frecuencia son poco conocidos por la población y por los potenciales prestadores de servicios los mecanismos dirigidos a implementar las actividades para concretar su realización. Algunos de los problemas más relevantes al respecto son el bajo nivel de conocimiento del mercado potencial, de nociones de administración, de las formas de comercialización de los productos turísticos, de acceso a financiamiento y de capacitación. La creación y fortalecimiento de micro y pequeñas empresas orientadas al turismo rural permitiría incidir en el desarrollo turístico regional y sentar las bases para un crecimiento que reduzca las externalidades negativas vinculadas con los modelos turísticos tradicionales.

Las asociaciones de pequeñas empresas o de pequeños productores alrededor de algún producto o servicio, como la preparación de alimentos, se ha convertido en una estrategia favorable al desarrollo local (Vandecandelaere y Abis, 2012). En ese contexto, una medida (que no necesariamente requiere de certificación) son las rutas gastronómicas o 
alimentarias, que se desligan de los restaurantes. Una ruta gastronómica es definida como "un itinerario que permite reconocer y disfrutar de forma organizada el proceso productivo agropecuario, industrial y la degustación de la cocina regional considerada una expresión de la identidad cultural regional” (Barrera y Bringas Alvarado, 2009, p. 5). Pero las rutas alimentarias no debieran ser una trivialización turística de la cultura rural, sino un instrumento para el desarrollo de los territorios rurales, de modo que se integren los establecimientos agropecuarios, las agroindustrias y los restaurantes con una visión compartida del desarrollo y con normas de calidad que atiendan tanto al orden sanitario como a la autenticidad de la propuesta.

De acuerdo con Barrera y Bringas Alvarado (2009, p. 47), la construcción de las rutas alimentarias requiere de acciones y políticas que favorezcan el turismo de los alimentos, pero también que tomen en consideración elementos relevantes como: a) sensibilización de la población local en torno al valor de esos alimentos; b) promoción de una vinculación más activa entre los clúster de alimentos y bebidas, y los de turismo; c) desarrollo de productos turísticos memorables; d) un sistema de calidad para la oferta garantizando la inocuidad de los alimentos y la autenticidad de la propuesta; e) marcas de calidad referenciadas en origen y medidas de protección para los alimentos con identidad; f) capacitación, creación y desarrollo de asociaciones de la ruta; g) diseño y puesta en marcha de un plan estratégico con un plan de inversiones; h) investigación y desarrollo de un inventario de los recursos.

Sin duda, la organización alrededor de signos distintivos o de estrategias de comercialización como las rutas gastronómicas no solo involucra la realización de un plan de negocios, sino de un programa de desarrollo rural que tenga en cuenta, como inicio, la voluntad de participación de las comunidades rurales (Sauvage y Gámez, 2013), así como los efectos ambientales y sociales de la transformación productiva asociada con el turismo gastronómico rural. De otra manera, los esquemas de fomento público o privado difícilmente serán exitosos, o lo serán, aunque con una distribución desigual de los beneficios.

\section{Las posibilidades económicas de los signos distintivos}

En el comercio, la propiedad intelectual de los productos en general, y de las marcas en particular, confiere ventajas competitivas a los productores y brinda certidumbre al consumidor sobre los artículos que adquiere. Las formas de protección de los productos son distintas y variadas: Estados Unidos utiliza Do fundamentalmente para vinos, y mc para el resto de los productos; en Europa se suele emplear IG, MC, Do y marcas certificadas, dependiendo de los productos de que se trate; y en México se usa con más frecuencia mc y Do.

Así, a través del Instituto Mexicano de la Propiedad Industrial (IMPI), los derechos de propiedad industrial protegen dos rubros de creaciones en México: los signos distintivos y las invenciones. "Los Signos Distintivos son todos aquellos símbolos, figuras, vocablos o expresiones que se utilizan en la industria o en el comercio para distinguir un producto, servicio o establecimiento, de otros de su misma especie, clase o actividad en el mercado" 
(Instituto Mexicano de la Propiedad Industrial, 2016, p. 11), y reciben protección mediante las marcas, avisos y nombres comerciales, y las Do.

La Do es el nombre de un país, una región o un lugar determinado, que se usa para designar a un producto originario, cuyas cualidades y características se deben exclusivamente al medio geográfico, incluidos factores naturales como geografía, clima o materia prima, y factores humanos como mano de obra, arte, ingenio y tradición, entre otros (Granados y Álvarez, 2004; Secretaría de Economía, 2018). En nuestro país, los gobiernos estatales, municipales o las asociaciones de productores pueden solicitar tal protección, pero cuando se otorga a una Do, el titular es el Estado mexicano.

De 1997 a 2018, las Do mexicanas llegaron a 16, entre ellas cinco destilados (tequila, mezcal, bacanora, sotol y charanda), ocho productos agrícolas (mango Ataulfo del Soconusco de Chiapas, café de Veracruz, café de Chiapas, chile habanero de la Península de Yucatán, chile de Yahualica, vainilla de Papantla, cacao de Grijalba y arroz del estado de Morelos), dos artesanías (maderas y productos de Olinalá, y cerámica de Talavera) y joyería de Ámbar de Chiapas (Instituto Mexicano de la Propiedad Industrial, 2018a). Así, en México, productos con Do como el tequila, o algunos quesos como el Cotija y el Adobera, son elaborados en entornos geográficos muy particulares, y sus características gastronómicas son mundialmente conocidas.

Sus objetivos son, entre otros, establecer normas o un código de prácticas o reglamento de uso para generar sistemas de trazabilidad, verificación y control a fin de garantizar calidad y conformidad; otorgar al producto un valor agregado que se ve reflejado en el precio; favorecer su uso y aprovechamiento y generar ganancias económicas importantes en la comercialización y exportación de los productos; impedir la competencia desleal en la forma de imitaciones o falsificaciones; crear un efecto de derrama económica, incluso en el ámbito turístico; difundir entre consumidores y comercializadores el producto y su calidad; identificar las características del producto y evaluar si tiene posibilidades en los mercados internos y externos.

El registro de las $\mathrm{MC}$ se otorga a petición de agrupaciones formalmente constituidas que reúnan a productores, fabricantes, prestadores de servicios, organizaciones o grupos de personas legalmente establecidos. Al día de hoy, el IMPI ha concedido 174 registros de Mc a asociaciones o sociedades en el país, que distinguen productos agroalimentarios, artesanías, cerámicas, sombreros, ropa y muebles, entre otros (Instituto Mexicano de la Propiedad Industrial, 2018b), en función del:

origen geográfico, el material, el modo de fabricación u otras características comunes de los bienes y servicios de las distintas empresas que utilizan la marca colectiva. El propietario de la misma puede ser una asociación de la que son miembros esas empresas o cualquier otra entidad, ya sea una institución pública o una cooperativa [Organización Mundial de la Propiedad Intelectual, s. f., s. p.].

A diferencia de la Do, que permite a los consumidores conocer la procedencia geográfica de los productos identificados con ella -así como que la calidad proviene de esa 
procedencia-, las mc dan a conocer a los consumidores que los que productos y/o servicios de quienes pertenecen a una misma agrupación comparten determinadas características. En ese sentido, reducen las desventajas en la comercialización que suelen enfrentar los pequeños productores, y les proporcionan un marco para la cooperación. Dado que el establecimiento de normas, criterios y una estrategia común es indispensable para el registro de las Mc, la Organización Mundial de la Propiedad Intelectual (s. f.) resalta su beneficio como instrumento de desarrollo local.

Sin embargo, estudios sobre casos incluso emblemáticos del uso de signos distintivos en México, como el queso Cotija, muestran que las figuras de protección legal no resuelven del todo la indefensión de los productores artesanales. Por ello, se ha adelantado la necesidad de que los marcos legales e institucionales mexicanos se adecuen a las diferentes condiciones de los campesinos y artesanos del país (Barragán López, 2016, pp. 107-108). Es decir, la protección que ofrecen los signos distintivos no está orientada a atender la naturaleza especial de los productos y servicios derivados de las creaciones y tradiciones indígenas o artesanales del país; ni el contexto institucional favorece su aplicación adecuada. Esa situación pone a las comunidades y a su patrimonio en condiciones de vulnerabilidad ante imitadores e industrias consolidadas.

Más aún, la integración a los esquemas de mercado del patrimonio comunitario (indígena o artesanal), como el alimentario, ha sido cuestionada sobre la base de que la valoración (para la comercialización) implica una apropiación cultural; y, por consecuencia, es un ejercicio de poder que no necesariamente queda bajo el control de los propietarios originales. De ese modo, la conexión entre las políticas de desarrollo y los alimentos no es directa y corren el riesgo de ser exotizados, trivializados y descontextualizados (Contreras, Ramírez de la 0 y Thomé Ortiz, 2016, pp. 329-330).

Esa preocupación es compartida en el marco europeo, en la medida en que los proyectos de desarrollo local (rural) anclados en el sector turístico promueven la dependencia económica de un modelo global basado en la diferenciación espacial en zonas productivas y áreas de recreación. En esa perspectiva, la especialización de regiones rurales españolas en el turismo (gastronómico, rural) es señalado como una tendencia hacia el "monocultivo" (Aguilar Criado, Merino Baena y Migens, 2003), con los riesgos que tal especialización conlleva en términos de dependencia y artificialidad.

Lo anterior contempla retos relevantes, para las comunidades en general, al momento de aprovechar las posibilidades y reducir las deficiencias de los signos distintivos para una efectiva protección legal y conservación de los patrimonios. No obstante, como destaca Rinaldi (2017) en el caso de la comida y la gastronomía, las salidas a ese conflicto dependen del tipo de política pública que se promueva, del tipo de estrategias de desarrollo que se realicen, del tipo de turistas que se atraiga y, en especial, del reconocimiento de que los elementos presentes en el territorio o en la comunidad deben ser considerados como un sistema y no como componentes individuales, desligados entre sí. 


\section{A. E. Gámez · E. Juárez · J. A. Guevara-Franco}

\section{Alimentos y bebidas con potencial de signos distintivos en Los Comondú}

Por su alto dinamismo, el turismo en Baja California Sur ha moldeado la economía estatal, y su relevancia no solo se refleja en el propio crecimiento de las esferas de alojamiento, alimentación y bienes inmuebles, sino que ha transformado el paisaje, los patrones migratorios y las relaciones sociales. Una de las razones de ello puede ser que, en un contexto de aridez y prácticamente nula actividad industrial, se ha difundido la percepción de que los beneficios del turismo sobrepasan sus consecuencias negativas. De manera paralela, aunque Sudcalifornia tiene 40 \% de su territorio bajo alguna categoría de protección, el conflicto entre las cuestiones ambientales y el crecimiento turístico no se ha abordado de forma integral (Ibarra Núñez et al., 2018). Efectos como el desmonte, la escasez de agua, el congestionamiento urbano y sus derivaciones son visibles desde ahora (Moreno Gómez, 2016) y, lo más probable, es que se exacerben en el futuro inmediato.

Asimismo, el aprovechamiento y difusión de los aspectos culturales regionales (como la gastronomía) es incipiente, ${ }^{1}$ no habiendo sido suficientemente integrado a la oferta turística, en especial en las comunidades rurales. Pese a ello, hay un área de oportunidad aprovechable considerando una tendencia positiva de los hogares estadounidenses - de donde se alimenta predominantemente el sector turístico sudcaliforniano- a participar en actividades culturales (Consejo de Promoción Turística de México, 2008).

En el caso de Baja California Sur, se pueden identificar más de 25 productos alimentarios frescos o procesados que tienen características diferenciales y que son reconocidos por los consumidores locales por su origen geográfico de algunas zonas del estado. De ellos, al menos cinco son derivados lácteos, cuatro derivados cárnicos, cinco frutas procesadas, dos frutas frescas, cuatro platos preparados, dos bebidas alcohólicas y, al menos, dos dulces típicos; esto sin considerar granos y tubérculos que forman parte de la gastronomía del rancho sudcaliforniano (Guevara-Franco, 2018). El sistema contemporáneo de ranchos proviene de los asentamientos estimulados por los misioneros jesuitas en su proceso de evangelización y colonización de la península de Baja California en el siglo xVII. En un contexto de aridez y aislamiento, misioneros y rancheros se establecieron junto a las escasas fuentes superficiales de agua, lo cual transformó la demografía de la región por la extinción de los indígenas, y del paisaje con las misiones y la construcción de los oasis (Cariño, 2001).

Los Comondú constituye uno de los oasis de mayor tamaño y mejor conservado de los 184 presentes en la península de Baja California (Arriaga y Rodríguez-Estrella, 1997), y es representativo de la historia, problemática y potencialidad de estos sistemas (Tenza, Pérez, Martínez-Fernández y Giménez, 2017). La población total de los dos núcleos de población asociados al oasis -San José y San Miguel de Comondú-, así como de los ranchos

Existen varias obras dedicadas a la representación visual de la naturaleza sudcaliforniana; dentro de las muy escasas sobre gastronomía, véase Macías Gómez (2015). 
aledaños, es de 257 habitantes (Secretaría de Desarrollo Social, 2013). En torno al oasis se organiza un sistema tradicional de ganadería extensiva de ganado bovino y caprino. Empero, en años recientes, desde la política pública se ha estimulado la actividad turística rural como un mecanismo de dinamización económica (Gámez, Angeles y Juárez, 2013; Ivanova, Gámez, Domínguez y Ramírez, 2013).

El principal ingreso de los productores en San Miguel y San José de Comondú (en esta última localidad se ubica una misión jesuita) es la venta de queso seco salado, seguida por la venta de cabrito y becerro. Sin embargo, sus factores más limitantes son la vulnerabilidad ante el alargamiento de las épocas de sequía, el alto intermediarismo, el abigeato, la depredación, así como la falta de organización de los productores, de financiamiento y de canales adecuados de comercialización. A ello se añade la ausencia de parámetros de calidad e inocuidad en el sector primario que permita a los productores locales competir en el mercado y que alienten la transformación agroindustrial. De los productos elaborados en la región destacan el queso, los dulces y algo de vino, que complementan los ingresos en esas economías casi de autosubsistencia.

La caprinocultura es una actividad rural socioeconómicamente importante en Baja California Sur, de la cual dependen directa e indirectamente cientos de familias. La producción de queso blanco oreado de cabra se realiza a pie de rancho. La elaboración del queso seco de cabra comprende los pasos básicos de clarificación, cuajado, salado, desuerado, y prensado en moldes fabricados con madera de la región. La leche proviene de cabras, principalmente, de la raza Nubia y sus cruzas con Saanen, Toggenburg y Alpina, adaptadas mejor a climas secos y alimentadas en su mayoría con vegetación silvestre. El queso se deja orear por alrededor de 15 días, y la falta de condiciones de refrigeración en la zona explica las altas concentraciones de sal para conservar el producto (Tapia Rendón, 2013).

Este queso es bien identificado por los consumidores locales, por su localización geográfica, como queso seco de Los Comondú, debido a que su producción se restringe al oasis conformado por las dos poblaciones sudcalifornianas mencionadas. Este queso es sensorialmente preferido por el consumidor por su sabor, olor y apariencia general. No obstante, su calidad microbiológica es baja, toda vez que es preparado con leche cruda de cabra, sin pasteurizar. En la actualidad, el queso se comercializa a través de intermediarios y, en su mayoría, es enviado a Sinaloa, Sonora y Jalisco. Este producto es poco conocido en las ciudades de Baja California Sur y no está disponible en restaurantes ni hoteles de los corredores turísticos del estado.

La organización de productores alrededor de la defensa de la calidad del producto en el marco normativo e institucional puede acelerar el registro y protección del "queso seco de cabra de Los Comondú”. Dadas las condiciones locales, ello mejoraría la rentabilidad de quienes lo producen, pero se requeriría de estudios de caracterización física-química, organoléptica y microbiológica que definan con claridad los métodos de producción y las características que dieran lugar, por ejemplo, a una mc; lo cual podría ser un ejercicio más realizable en el corto plazo que, por ejemplo, una Do. Asimismo, haría procedente que los productores locales se organizaran para regular la presentación y comercialización del queso. 


\section{A. E. Gámez · E. Juárez · J. A. Guevara-Franco}

Otro producto con potencial de mc es el vino misional, elaborado a partir de una variedad de uva conocida por los pequeños vitivinicultores artesanales de la región como "misional”. Esta se asocia con la uva que se utilizaba para la preparación del vino de consagrar en las misiones jesuitas, aunque no se sabe a ciencia cierta el tiempo de existencia de este producto. Solo algunos vestigios de equipos como prensas, filtros y fermentadores realizados a base de piel bovina en un marco de madera indican que se elabora tradicionalmente (Guevara et al., 2013).

Hoy en día, se empieza a reconocer la calidad del producto y, alrededor del vino, se Ileva a cabo un festival del vino misional de Los Comondú, que se extiende a otros oasis aledaños, y en sus ediciones ha tenido la participación de sommeliers de España y México. Esto se ha convertido en un atractivo turístico y toda la oferta (si bien es pequeña) es vendida a turistas y visitantes a los poblados, e incluso en ocasiones es distribuida al menudeo en la ciudad de La Paz. El producto es sensorialmente atractivo y se puede comparar con otros vinos jóvenes de calidad; pero, pese a que tiene una calidad organoléptica bien definida, la alternativa de constituirse en un producto de Mc o de Do implica determinar, en principio, si el producto no representa un riesgo para la salud. Ello, a la vez, requiere destacar su inocuidad y las mejores características fisicoquímicas. Los vinos jóvenes, de crianza, son bebidas alcohólicas de acuerdo con la NMX-V-012-1986, por lo cual la cantidad de alcohol debe estar bien especificada para el consumidor mediante una etiqueta en una mejor forma de presentación.

Es necesario, entonces, plantearse algunas estrategias que mejoren la calidad e inocuidad del producto y eleven la producción de uva mediante la implementación de prácticas de producción agrícola y la reducción de riesgos de contaminación durante las etapas fenológicas del cultivo. La recomendación es que se realice un diagnóstico en este rubro, donde se determinen las características de la variedad de uva, las mejores prácticas agronómicas, se clasifiquen los viñedos y se haga un inventario de las cepas y, en su defecto, se busquen alternativas para incrementar el número de cepas.

Asimismo, se debe capacitar en el uso del agua, y ofrecer cursos sobre manejo vegetativo del cultivo, buenas prácticas agrícolas y tratamiento poscosecha de la uva, así como sobre prácticas de higiene en la elaboración del vino y factores que afectan su calidad y métodos de producción. En cuanto a la infraestructura, es menester desarrollar proyectos para el establecimiento de pequeñas bodegas que cumplan con los requisitos de higiene en la elaboración del producto. Respecto al queso de cabra, han de tomarse medidas similares. De ser de interés, se puede apoyar investigación que determine los microorganismos benéficos que favorecen la fermentación y así distinguir un cultivo iniciador de la fermentación del vino y del queso para esa pequeña región.

Como se ha indicado, en ambas comunidades el queso de cabra y el vino misional son productos con un valor significativo para la economía familiar en la región. Sin embargo, pese a que la producción de queso de cabra está más generalizada que la de vino misional, es esta en la que se ha centrado la política de promoción de turismo rural en la zona. Además, a casi ocho años de iniciada una explícita política de aprovechamiento turístico del 
pasado misional en Los Comondú, los resultados son aún ambiguos y sigue siendo preciso replantear sus procesos de organización y de producción para revalorar el patrimonio gastronómico, así como cuidar la inocuidad de los productos.

En todo caso, independientemente de proceder a la organización de productores alrededor de una mc u otro signo distintivo, un elemento prioritario es garantizar la inocuidad de los productos locales. Tanto el queso como el vino son productos conocidos, ya comercializados y que, de cierta forma, han sido patrimonializados a través de una larga historia de producción artesanal y de las iniciativas de turismo rural en Los Comondú y en zonas similares de los últimos años.

\section{Conclusiones}

Algunos alimentos, como el queso de cabra y el vino misional producidos en zonas rurales serranas en Baja California Sur, ofrecen una oportunidad para aprovechar productos agroalimentarios tradicionales a fin de mejorar las condiciones de vida de las poblaciones locales, ya que se encuentran vinculados con tradiciones de producción artesanal, con zonas geográficas específicas, y tienen características de alta calidad sensorial. El aislamiento geográfico y la conformación del territorio por grandes cañadas y valles delimitados unos de otros mantienen una riqueza gastronómica centenaria que se ha conservado desde la época misional. Sin embargo, para formalizar su aprovechamiento a través de signos distintivos y potenciar sus posibilidades de comercialización, aún es necesario reducir la variabilidad de productos, y generar estudios de ubicación geográfica, calidad e inocuidad, así como estrategias de intervención para ligar esos esfuerzos a un turismo rural incipiente.

Pese a la existencia de políticas de fomento del turismo rural y de comercialización de los productos locales en Los Comondú desde hace casi una década, no se ha avanzado en el mejoramiento de las condiciones con que se realiza su oferta. En particular, destaca la importancia de establecer esquemas de capacitación a los productores locales para un manejo adecuado de los alimentos en todo su proceso. La finalidad de esto es que los estudios que se realicen tengan una aplicación efectiva, lo cual implica identificar a los integrantes del sector interesados en desarrollarlas, además de ubicar las fuentes de apoyos diversos para la puesta en práctica de esas actividades alternativas. En este sentido, a partir de investigaciones sobre el manejo pecuario y agrícola, se pueden realizar mejoras a los procesos productivos, así como garantizar la inocuidad alimentaria y la conveniencia de procesos de certificación en beneficio de los productores y comunidades locales. Esto tendría que ir aparejado de capacitación y conocimiento en el tema turístico, y de mecanismos para enfrentar los efectos socioculturales que van asociados con la introducción del turismo en la vida de las comunidades y las familias.

Algunas recomendaciones que pueden adelantarse son llevar a cabo estudios que determinen la calidad tecnológica, sensorial y microbiológica, que aseguren su inocuidad. Ningún plan de comercialización o de establecimiento de rutas alimentarias será realmente viable si en el lugar no se cambian las formas como se realiza la producción. Entre otros 


\section{A. E. Gámez · E. Juárez · J. A. Guevara-Franco}

factores esto se relaciona con: a) las prácticas productivas (falta de inocuidad); b) la actitud de los productores y pobladores respecto a sus formas de organización, capacitación, y percepción de su patrimonio (tanto tangible como intangible); y c) el tipo de intervención efectuada por los diferentes niveles de gobierno.

Revisar el marco legal y la organización de los signos distintivos, como Do y Mc, y adecuarlo a las características de los productos sudcalifornianos, puede ser una estrategia para facilitar las posibilidades de mc de productos de Los Comondú. En México existe experiencia incluso con productores pequeños que puede ser compartida. Por otro lado, la promoción y apropiación de las marcas por parte de los consumidores fortalecería la concientización de los productores respecto a la importancia de valorar y diferenciar sus productos con base en la calidad, su origen y tradición. Esto bien podría contribuir al fortalecimiento del incipiente turismo rural en la zona.

Las características ecosistémicas de Los Comondú hacen poco factible incrementar en una escala masiva la producción y comercialización de sus productos agropecuarios. Empero, el turismo rural ligado a rutas alimentarias en pequeña escala o eventualmente en mc permitiría rescatar la idea de aprovechar la calidad de productos como el queso y el vino, a través de estudios de laboratorio sobre sus condiciones e inocuidad. Además, es pertinente promover una política de desarrollo rural que integre la conformación histórica y sociocultural de ambas comunidades, las relaciones con el exterior y la influencia de agentes extralocales, las condiciones en que se realizan las actividades económicas, los usos de recursos clave como el agua, y la cultura productiva local. Un esquema de fortalecimiento productivo integral que permita el desarrollo y empoderamiento de la propia comunidad puede ser potenciado con un aprovechamiento alterno de los recursos locales. Dado que Los Comondú no son un caso aislado en la búsqueda de opciones para el cumplimiento de esos objetivos, un esquema así podría extrapolarse a comunidades rancheras y de oasis similares en el resto del estado.

\section{Fuentes consultadas}

Aguilar Criado, E., Merino Baena, D. y Migens, M. (2003). Cultura, políticas de desarrollo y turismo rural en el ámbito de la globalización. Horizontes Antropológicos, 9(20), 161183. Recuperado de https://dx.doi.org/10.1590/S0104-71832003000200009

Arriaga, L. y Rodríguez-Estrella, R. (1997). Los oasis de la península de Baja California. La Paz, Baja California Sur: Centro de Investigaciones Biológicas del Noroeste.

Barragán López, E. (2016). Entre oportunidades y obstáculos. Lo que devela el proceso de inserción del queso Cotija artesanal en la economía formal. EntreDiversidades. Revista de Ciencias Sociales y Humanidades, 7, 84-111.

Barrera, E. y Bringas Alvarado, O. (2009). La ruta de la sal prehispánica de Zapotitlán Salinas, una estrategia de desarrollo comunitario basada en los alimentos con identidad local. Cultura, Tecnología y Patrimonio, 4(7), 33-48.

Breceda, A., Galina, P. y Cortés, P. (2010). Estrategias de conservación para los oasis de Baja California: un estudio de caso. Taller de Dunas Costeras y Humedales: Futuro y 
Conservación. Comisión Nacional de Áreas Naturales Protegidas, 2 de septiembre, San José del Cabo, Baja California Sur. Recuperado de http://ramsar.conanp.gob. $\mathrm{mx} /$ talleres.php

Brenner, L. y Aguilar, A. G. (2002). Luxury tourism and regional economic development in Mexico. The Professional Geographer, 54(4), 500-520. doi:10.1111/00330124.00346

Cariño, M. (2001). La oasisidad, núcleo de la cultura sudcaliforniana. Gaceta Ecológica, 60, 57-69.

Consejo de Promoción Turística de México. (2008). Análisis del mercado internacional del turismo de cultura 2007. México: Autor.

Consejo Nacional de Ciencia y Tecnología. (2018). Fondo Mixto CONACYT-Gobierno del Estado de Baja California Sur. Convocatoria BCS-2018-01 "Desarrollo e Localidades Serranas de Baja California Sur". Demanda Específica Demanda BCS-2018-01-01 Programa de Desarrollo Sustentable de las Localidades Serranas de Baja California Sur. Recuperado de https://www.conacyt.gob.mx/index.php/el-conacyt/ convocatorias-y-resultados-conacyt/convocatorias-fondos-mixtos-contituidos / convocatorias-fondos-mixtos-constituidos-baja-california-sur/convocatorias-abiertas-fondos-mixtos-constituidos-baja-california-sur / 18-01-fomix-bcs / 17870-fomix-bcs-18-01-dem-espec/file

Contreras, D. J., Ramírez de la O, I. L. y Thomé Ortiz, H. (2016). Entre el desarrollo económico y la apropiación cultural. Apuntes para el debate sobre la valorización de alimentos emblemáticos. Estudios Sociales, 47(25), 327-347.

Coordinación General de Desarrollo Sustentable. (2015). Proyecto estratégico de desarrollo sustentable oasis sudcalifornianos. La Paz, Baja California Sur: Gobierno del Estado de Baja California Sur. Recuperado de https://docplayer.es/11480713-Proyecto-estrategico-de-desarrollo-sustentable-oasis-sudcalifornianos.html

Dávila López, A. (2014). Centros Integralmente Planeados (CIPs) en México. Las piezas del proyecto turístico de FONATUR. VI Seminario Internacional de Investigación en Urbanismo, Barcelona-Bogotá, junio 2014. Recuperado de https://upcommons.upc. edu/bitstream/handle/2099/15985/075_BCN_Davila_Arturo.pdf

Gámez, A. E. (ed.). (2013). Opciones de desarrollo en el oasis de Los Comondú, Baja California Sur, México. México: Instituto Sudcaliforniano de Cultura/Universidad Autónoma de Baja California Sur/Consejo Nacional de Ciencia y Tecnología.

Gámez, A. E., Angeles, M. y Juárez, E. (2013). Turismo y emprendedurismo en regiones rurales de México: una crítica al rol del capital social en el desarrollo local. El caso del oasis de Los Comondú. TURyDES. Revista de Investigación en Turismo y Desarrollo Local, 6(14). Recuperado de http://www.eumed.net/rev/turydes/14/turismo-regiones-rurales-mexico.pdf

García Henche, B. (2005). Características diferenciales del producto turismo rural. Cuadernos de Turismo, 15, 113-133.

Granados, L. y Álvarez, C. (2004). Estudio introductorio sobre la viabilidad de las denominaciones de origen de los productos agroalimentarios en Costa Rica a partir de la experiencia en la Comunidad Autónoma de Galicia. Revista Gallega de Cooperación Científica Iberoamericana, 10, 9-19. 


\section{A. E. Gámez · E. Juárez · J. A. Guevara-Franco}

Guevara, J., Juárez, E., Gámez, A. E. y Rojas, M. (2013). Los Comondú: opciones de agregación de valor a los productos locales. En A. E. Gámez (ed.), Opciones de desarrollo en el oasis de Los Comondú, Baja California Sur, México (pp. 181-208). México: Instituto Sudcaliforniano de Cultura/Universidad Autónoma de Baja California Sur/ Consejo Nacional de Ciencia y Tecnología.

Guevara-Franco, A. (2018). Documento de trabajo [mimeo]. La Paz, Baja California Sur: Universidad Autónoma de Baja California Sur, Departamento Académico de Ciencia Animal y Conservación del Hábitat.

Ibarra Núñez, E., Gámez, A. E. y Ortega-Rubio, A. (2018). Impacto territorial del turismo en Zonas Prioritarias para la Conservación y Ecosistemas Prioritarios de Baja California Sur, México. Sociedad y Ambiente, 6(17), 33-58.

Instituto Mexicano de la Propiedad Industrial. (2016). Guía del usuario para el Registro de Marcas, Avisos y Publicación de Nombres Comerciales. México: Autor. Recuperado de https://www.gob.mx/cms/uploads/attachment/file/54262/GDU_Marcas.pdf

Instituto Mexicano de la Propiedad Industrial. (2018a). Servicios que ofrece el IMPI, Marcas, Denominaciones de Origen e Indicaciones Geográficas. México: Autor. Recuperado de https://www.gob.mx/impi/acciones-y-programas/servicios-que-ofrece-el-impi-marcas-denominaciones-de-origen-e-indicaciones-geograficas

Instituto Mexicano de la Propiedad Industrial. (2018b). Ventajas de contar con una marca-colectiva. Recuperado de https://www.gob.mx/impi/articulos/ventajas-de-contar-con-una-marca-colectiva

Ivanova, A., Gámez, A., Domínguez, W. y Ramírez, E. (2013). Turismo sustentable y desarrollo local en el oasis de los Comondú. En M. Cariño, A. Breceda, A. Ortega y L. Castorena (eds.), Evocando al edén: conocimiento, valoración y problemática del oasis de los Comondú (pp. 481-516). Barcelona: Icaria.

Macías Gómez, B. E. (2015). Gastronomía de los zafiros. Arte que surge del mar y el desierto de Sudcalifornia. México: Instituto Sudcaliforniano de Cultura.

Mckercher, B. y Du Cros, H. (2002). Cultural Tourism. The Partnership between Tourism and Cultural Heritage Management. Nueva York: The Haworth Hospitality Press.

Millán Vázquez de la Torre, M. G. y Agudo, E. M. (2010). El turismo gastronómico y las Denominaciones de origen en el sur de España: Oleoturismo. Un estudio de caso. Pasos. Revista de Turismo y Patrimonio Cultural, 8(1), 91-112. Recuperado de http:// www.pasosonline.org/Publicados/8110/PS0110_8.pdf

Monterrubio, C., Osorio, M. y Benítez, J. (2018). Comparing enclave tourism's socioeconomic impacts: A dependency theory approach to three state-planned resorts in Mexico. Journal of Destination Marketing \& Management, 8, 412-422.

Moreno Gómez, G. (2016). Capacidad de carga urbana y análisis espacio-temporal del crecimiento de La Paz, B.C.S., México (Tesis de maestría en Ciencias Sociales con orientación en Desarrollo Sustentable). Universidad Autónoma de Baja California Sur, La Paz.

Organización Mundial de la Propiedad Intelectual. (s. f.). Las marcas colectivas. Recuperado de http://www.wipo.int/sme/es/ip_business/collective_marks/collective_marks.htm

Organización Mundial del Turismo. (2018). Notas metodológicas de la base de datos de estadísticas de turismo, edición 2018. Madrid: Autor. 
Peninsular Digital. (21 de diciembre de 2011). Invierte gobierno 13.5 mdp en oasis Mulegé. Peninsular Digital. Recuperado de http://peninsulardigital.com/municipios/ invierte-el-gobierno-13-5-mdp-en-oasis-de-mulege/63429

Rinaldi, C. (2017). Food and gastronomy for sustainable place development: A multidisciplinary analysis of different theoretical approaches. Sustainability, 9(10), 1748. doi: $10.3390 /$ su9101748

Rosas Mantecón, A. (2006). Turismo y patrimonio: realidades y espejismos de una promesa. En L. Arizpe (ed.), Retos culturales de México frente a la globalización (pp. 473-497). México: Porrúa.

Sauvage, A. y Gámez, A. E. (2013). Desarrollo, identidad cultural y turismo en los oasis de Baja California Sur, México. Pasos. Revista de Turismo y Patrimonio Cultural, 11(1), 159-172.

Secretaría de Desarrollo Social. (Julio, 2013). Catálogo de Localidades. Resumen municipal. Municipio de Comondú. Recuperado de http://www.microrregiones.gob.mx/catloc $/$ Default.aspx?tipo=clave\&campo $=$ mun\&valor $=03$

Secretaría de Economía. (2 de julio de 2018). México cuenta con 16 denominaciones de origen. Recuperado de https://www.gob.mx/se/articulos/mexico-cuenta-con-16-denominaciones-de-origen

Tapia Rendón, N. A. (2013). Caracterización de la calidad tecnológica e inocuidad del queso seco de cabra producido en el oasis de San Miguel y San José de Comondú, BCS (Tesis de médico veterinario zootecnista). Universidad Autónoma de Baja California Sur, Departamento de Zootecnia, La Paz.

Tenza, A., Pérez, I., Martínez-Fernández, J. y Giménez, A. (2017). Understanding the decline and resilience loss of a long-lived social-ecological system: Insights from system dynamics. Ecology and Society, 22(2), 15. Recuperado de https://doi.org/10.5751/ ES-09176-220215

Vandecandelaere, E. y Abis, S. (2012). Food, tourism and regional authorities. En Mediterra (pp. 423-442). París: Presses de Sciences Po. 